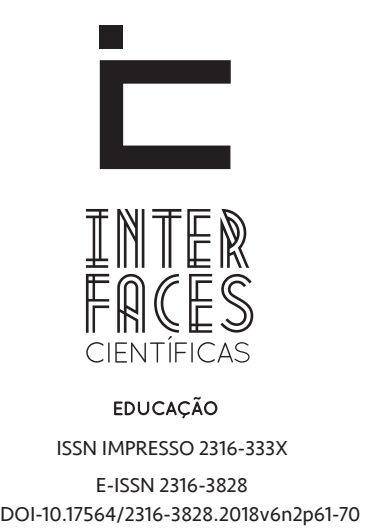

\title{
RELAÇÕES INTERPESSOAIS ENTRE ALUNOS E PROFESSORES EM UMA ESCOLA ESTADUAL DE VARGEÃO [SC]
}

INTERPERSONAL RELATIONSHIPS BETWEEN STUDENTS AND TEACHERS IN A PUBLIC SCHOOL AT VARGEÃO [SC]

RELACIONES INTERPERSONALES ENTRE ALUMNOS Y PROFESORES EN UNA ESCUELA ESTADUAL DE VARGA [SC]

Daiane Lando Peruzzo

Angélica Siqueira²

Sonia Marta Alberici ${ }^{3}$

\section{RESUMO}

0 artigo tem por objetivo verificar quais são os fatores que permeiam as relações interpessoais entre professor e aluno em uma escola estadual localizada na cidade de Vargeão (SC). Obteve-se os dados por base de questionários distintos entre professores e alunos. Os resultados apontaram diferenças significativas nas respostas dos questionados e também similaridades, pelo que se comprovam como ocorrem, de fato, as relações interpessoais. 0 empenho de todos os envolvidos no processo das relações interpessoais foi um condicionante relatado que possibilita melhoria, além de qualidades essenciais dos sujeitos nas relações humanas - cite-se respeito e diálogo. Nesta busca

pela verificação de como se estabelecem as relações escolares entre os sujeitos estudados, procura-se o que é benéfico e o que pode ser modificado, mas, em momento algum, a intenção é interferir, e sim propor uma reflexão em que quem decide são as próprias pessoas nos objetivos de ensino-aprendizagem entre professor e aluno.

\section{PALAVRAS-CHAVE}

Professor. Aluno. Relações interpessoais. Ensino-aprendizagem. 


\section{ABSTRACT}

The article aims is check which are the factors that permeate interpersonal relationships between teacher and students in a public school situated in Vargeão (SC). There was obtained the information based on different questionnaires between teachers and students. The results showed significant differences in answers of the researched and also similarities, so it proved as they occur, in fact interpersonal relationships. The effort of all involved in the process of interpersonal relationships was a reported condition that makes it possible improvement, in addition to essential qualities of the subjects in humans relations-quote is res- pect and dialogue. In this search by checking how to stablish the relationship between school subjects studied, looking what is good and what can be changed, but, at any time, the intention is to interfere, but propose a reflection on who decides which are the very people in the teaching-learning aims between teacher and student.

\section{KEYWORDS}

Teacher. Student. Interpersonal relationships. Teaching-learning.

\section{RESUMEN}

El artículo tiene por objetivo verificar cuales son los factores que impregnan las relaciones interpersonales entre profesores y alumnos en una escuela estadual localizada en la ciudad de Vargeão (SC). Se obtuve datos utilizando distintos cuestionarios entre profesores y alumnos. Los resultados muestran diferencias significativas en las respuestas de las encuestas y también similitudes, por lo que se comprueban, de facto, como ocurren las relaciones interpersonales. El compromiso de todos los envueltos en el proceso de las relaciones interpersonales fue un condicionante relatado que posibilita mejoría, además de calidades esenciales de los sujetos en las relaciones humanas - referente a res- peto y dialogo. En esta búsqueda por la verificación de cómo se establecen las relaciones escolares entre los sujetos estudiados, se procura lo que es benéfico y lo que se puede cambiar, pero, en momento alguno, la intención es interferir, y sí proponer una reflexión en que quien decide son las propias personas en los objetivos de enseñanza-aprendizaje entre profesores y alumnos.

\section{PALABRAS CLAVE}

Profesor. Alumno. Relaciones interpersonales. Enseñanza-aprendizaje. 


\section{INTRODUÇ̄̃O}

0 presente artigo aborda a importância das relações interpessoais entre professores e alunos no ambiente escolar e sugere que o contato social nesse meio contribui para um melhor desenvolvimento da aprendizagem, favorecendo uma maior construção social e intelectual. Tem por objetivo verificar quais são os fatores que permeiam as relações interpessoais entre professor e aluno. A instituição escolhida foi uma escola estadual localizada na cidade de Vargeão-SC. 0 público-alvo da nossa pesquisa foram as turmas da $8^{a}$ série vespertino do ensino fundamental e da $2^{\mathrm{a}}$ série matutino do ensino médio, com faixa etária de 14 a 17 anos, e cinco professoras. Foram aplicados dois questionários distintos (aluno e professor), contendo dez questões abertas e fechadas.

Para a organização dos dados, considerando que a pesquisa foi realizada com professores e alunos, optou-se por analisar, primeiramente, as respostas dos professores e, em seguida, a dos alunos, para finalmente fazer uma reflexão sobre as respostas apresentadas por ambos os grupos apresentados. As professoras foram enumeradas como P1, P2, P3, P4 e P5, para melhor entendimento das respostas.

\section{OLHARES SOBRE AS RELAÇÕES INTERPESSO- AIS ENTRE ALUNOS E PROFESSORES}

Exige-se, cada vez mais, que os professores sejam profissionais capazes de lidar com diversas situações, principalmente nas questões pertinentes aos alunos; por isso, da preocupação com a formação docente (profissional e humana). Rotineiramente, torna-se indispensável a socialização da matéria e interação nas aulas, sendo isso uma função primordial para os professores, na relação interpessoal aluno e professor.

As professoras apresentam, com formação de pós-graduação, P3 e P5, e somente com graduação, P1, $\mathrm{P} 2$ e $\mathrm{P} 4$, considerando-se que todas têm formação para lecionar. 0 tempo de serviço das professoras questionadas teve uma média de 3,3 anos (P1, P2, P3 e P4), e uma professora (P5) tem maior experiência, com 26 anos de magistério.

Vale ressaltar que o trabalho no ensino está baseado principalmente nas relações interpessoais entre professor e aluno. A partir disso, destacamos, mediante os resultados obtidos, que todas as questionadas apontam que as relações interpessoais têm influência direta sobre o aprendizado dos alunos, porém P3 destaca que "em muitos casos, os alunos se relacionam com os professores apenas para obter resultados quantitativos com as notas." Todas responderam ter respeito, ética, compreensão, e principalmente muito diálogo, "até mesmo conselhos para mudanças pessoais", acrescentando as divergências e oposições que fazem parte do crescimento e troca de conhecimentos.

Declararam que evitam conflitos, mas que esses ocorrem até sem querer. Procuram não ser rígidas demais, para não haver resistência por parte dos alunos. Em todas as situações, procuram compreender na totalidade, percebendo as diferenças e dificuldades dos alunos para poder repassar, da melhor maneira possível, o conhecimento. De acordo com Marchesi (2008, p. 11),

\begin{abstract}
A educação está sujeita a expectativas elevadas e a busca de solução imediatas para dificuldades que não se originam nas escolas, e para as quais não há uma resposta a curto prazo. Além disso, muitos dos problemas manifestam-se de formas antagônicas e divergentes, que evidenciam a existência de opções ideológicas, educacionais e profissionais diferentes. normal que existam essas controvérsias, por isso não é de estranhar que em muitos temas educacionais seja difícil de chegar a um acordo. Assim a tarefa de ensinar está imersa em diversos dilemas e contradições.
\end{abstract}

A respeito das relações serem importantes para o aprendizado do pré-adolescente e adolescente, apontou-se os pontos positivos e negativos nos estudos. No destaque para os aspectos positivos, destacou-se que o aprendizado melhora, o aluno assimila melhor o conteúdo, confia na profissional professora e, por vezes, ultrapassa suas barreiras pessoais. 
Em caso de rejeição do aluno por qualquer tipo de relação com a professora, $\mathrm{P} 1, \mathrm{P} 2, \mathrm{P} 4$ e P5, que tiveram essa situação, procuraram reverter em favor de uma relação construtiva, para conquistar a confiança e a amizade, conseguindo entender as atitudes dele. Com uma boa relação professoras e alunos, os estudantes têm maiores perspectivas quanto ao futuro; procuram informações com as professoras, para ter um bom direcionamento; buscam orientação fora da escola e também sobre cursos de aperfeiçoamento, formação técnica e em universidades.

Estudos destacam duas emoções positivas dos professores em relação aos alunos: o afeto por eles e a satisfação por seus progressos escolares. Contudo, as experiências emocionais negativas também são muitas. As duas mais comuns, ou pelo menos as mais presentes, são a frustração e a irritação - ambas podem ser oriundas de várias situações, como, por exemplo: a falta de apoio para a realização das tarefas, a falta de atenção e o mau comportamento dos alunos. Caso essa tensão toda permanecer durante um período de tempo, pode levar ao cansaço, ao abatimento e a um colapso emocional.

O enfrentamento com os alunos desordeiros, agressivos ou com graves problemas de conduta durante a aula, constitui uma das experiências mais negativas para os professores. A tensão que esses confrontos geram, seus efeitos no comportamento dos outros alunos e a quebra de ritmo do ensino complicam grandemente a docência, tornando-a cada vez mais difícil de suportar. (MARCHESI, 2008, p. 109).

Diante dessa situação, o professor fica dividido em dois polos: um seriam o castigo e a separação da turma, como forma de proteger os direitos dos outros alunos e os seus próprios direitos; o outro seria o de optar pelo diálogo, pela negociação e pelo compromisso, como a melhor maneira de conseguir os mesmos objetivos e recuperar o aluno. Um equilíbrio entre ambas as estratégias em benefício dos alunos talvez seja a atitude mais positiva nesses casos. Vejamos o relato de P5: "tem muita influência no aprendizado; quando o aluno gosta do professor, ele sempre consegue assimilar melhor o conteúdo".
Em relação à pergunta sobre pontos positivos na relação entre professor e aluno, P4 comenta que "um ponto positivo é que o aluno confia no profissional professor e, muitas vezes, ultrapassa suas barreiras pessoais". No que se refere aos aspectos negativos, P4 afirma que "se as relações são boas, os alunos esperam resultados quantitativos a partir do seu bom relacionamento com os professores, não necessariamente do seu esforço". P5 descreve que

[...] caso as relações não sejam boas, o aluno não tem motivação para os estudos, vai mal nas provas, e alguns, devido ao mau resultado, procuram tumultuar a aula. Sem as boas relações, os alunos não têm perspectivas para o futuro, ficam excluídos até mesmo pelos próprios colegas em sala de aula, não buscam cursos de aperfeiçoamento, formação técnica, cursos em universidades...

\section{E, segundo Marchesi (2008, p. 45)}

\begin{abstract}
Nem todos os professores valorizam os alunos do mesmo modo. A maioria dos estudos realizados sobre 0 tema conclui que existe uma relação positiva entre as expectativas favoráveis sobre os progressos dos alunos, especialmente quando são informados sobre ele, e seu rendimento escolar.
\end{abstract}

No que tange à gestão escolar, ela se baseia em uma concepção educacional que deriva do paradigma racional positivista, no qual prevalece uma relação sujeito-objeto sob o ponto de vista fragmentado. Esse modelo conservador de pensar fundamenta-se numa nova concepção de educação que recusa a hierarquização e valoriza as relações interpessoais entre os sujeitos iguais e, ao mesmo tempo, diferentes. Trata-se de um paradigma democrático emergente que valoriza 0 respeito às ideias e valores assumidos coletivamente, considerando a sociedade atual que almejamos.

Portanto, a gestão é um meio de mobilizar procedimentos para atingir objetivos para a organização, envolvendo aspectos pedagógico e administrativo, tendo em conta o conceito de direção, que é atributo e princípio da gestão, por meio da qual é canalizado o trabalho conjunto das pessoas, orientando-as e integrando-as rumo aos objetivos. 
A organização sofre forte influência que diz respeito aos comportamentos, às opiniões, às ações e às formas de relacionamentos que surgem espontaneamente no grupo escolar. Toda escola tem suas peculiaridades, que as tornam únicas, especialmente em razão de aspectos pedagógicos diferenciados. Mesmo sendo uma organização formal, há uma interação com a informalidade: nem todos os membros da escola pensam ou agem do mesmo modo.

Referente à gestão escolar, o ambiente escolar influencia nas relações interpessoais entre professores e alunos. Vale lembrar que em uma escola com clima satisfatório, as relações estabelecidas se tornam mais construtivas.

Percebe-se, observando as respostas dos professores, que todos gostam de trabalhar na escola e se dizem satisfeitos com as relações que ali permeiam. P1 e P3 estabelecem melhorias para o modo de gestão da escola, como, por exemplo: "que a gestão, ou melhor, os gestores precisam ser firmes quanto às regras e possíveis imparcialidades entre docentes e discentes, mantendo-se firmes nas decisões e punições, tendo como alicerce o PPP”. P1 sugere que a gestão promova locais para melhorar as relações, citou salas de teatro (que melhoram a expressividade dos alunos).

Diante de condicionantes estabelecidos como problemas financeiros, culturais e psicológicos que cada aluno traz consigo, as professoras analisam as peculiaridades dos seus alunos para poder compartilhar melhor os seus conhecimentos, cada uma com um olhar distinto, com sua lente.

Analisamos o relato de P1: "tomando conhecimento de cada fato e procurando saber se o aluno quer este auxílio. Compreender, procurar a melhor forma de auxiliar sem expor o mesmo". P2: "os assuntos são relacionados com o cotidiano do aluno, muitas vezes com debates em relação com sua vida pessoal”. Esses relatos nos revelam soluções similares: procuram conhecer melhor seus alunos, porque sabem que cada aluno tem uma história e classe social que os torna diferente e único, e, tais singularidades precisam ser respeitadas.

Em contraposição com a pergunta, $\mathrm{P} 3$ e $\mathrm{P} 4$ não colocam alternativas para melhorar o aprendizado e somente apontam os condicionantes financeiros sem muita interferência nos estudos. P3:

[...] talvez a esta pergunta coubesse uma interrogativa.
Concordo que, a partir do momento em que conhece-
mos nosso aluno, nos aproximamos mais dele, mas tam-
bém temos a ciência de que nem sempre o meio destrói
um caráter. Não somos ruins, por sermos carentes, nem
bons devido a uma boa condição financeira.

P4: deixou em branco a questão. P5: "nem sempre os meios influenciam na produção de conhecimento. Talvez não seja cem por cento, mas, principalmente, o financeiro não impede. Sempre busco conhecer para saber trabalhar e não diferenciá-los por isso". Analisando as respostas dos professores, é possível perceber que todos eles procuram ensinar de uma única maneira os seus alunos. Os fatores culturais, financeiros e religiosos, entre outros, não são empecilhos para o processo de ensino-aprendizagem dos alunos.

Os alunos, assim como os professores, também foram enumerados como A1, A2, A3 e assim sucessivamente. Vale ressaltar que, quando entramos na sala de aula, todos os alunos nos receberam calorosamente. Num primeiro momento, nós nos apresentamos, deixamos bem claro o motivo da nossa presença na sala de aula naquele dia e a importância do estudo das relações interpessoais entre professor e aluno. Todos os alunos presentes demonstraram interesse no assunto e aceitaram participar dos questionários. Depois da entrega dos questionários, fizemos uma breve releitura das questões, para solucionar eventuais dúvidas dos alunos.

Questionados há quanto tempo eles estudam na escola, fizemos uma média das respostas obtidas, ficando em quatro anos, tendo em vista que, nessa escola, só estudam alunos do sexto ao terceiro ano do ensino médio.

Diante da frase: "É preciso respeitar o outro no seu modo de ser e, assim, garantir um bom relacionamento, possibilitando um clima de confiança". Analisando as respostas, é possível perceber uma compatibilidade de respostas entre as duas turmas ( $8^{\mathrm{a}}$ série e $2^{\mathrm{a}}$ série), sendo que todos os participantes consideraram o res- 
peito como sendo muito importante entre professor e aluno. Ainda, afirmam que melhora a convivência entre ambos e o aprendizado acontece mais facilmente.

Vejamos alguns relatos dos alunos. A10 ( $2^{\mathrm{a}}$ série) afirma que "a boa convivência entre alunos e professores é muito importante, pois, sem ela, fica mais difícil para o professor educar, e para o aluno aprender". A17 ( $8^{a}$ série) relata: "os alunos aprendem mais, os professores conseguem explicar o conteúdo e as notas dos alunos melhoram”. A23 ( $2^{\mathrm{a}}$ série) comenta:

Na minha opinião, o respeito é a base de qualquer relação, independente de qual e com quem for. 0 respeito em sala de aula é fundamental, pois devemos respeitar os professores que estão nos passando o conhecimento, e o respeito com os colegas, para um bom convívio.

A20 (2ª série) descreve: "na minha opinião, um saber respeitar o outro. Quanto ao modo que o professor tratar os alunos, os alunos vão tratar o professor, e isso vice-versa. Se o aluno quer ser respeitado, ele vai ter que respeitar”. A2 ( $8^{a}$ série) comenta: “respeito é importante, para poder haver um bom diálogo entre aluno e professor, para conversar caso o aluno não estela indo tão bem na matéria ou caso tiver dúvidas”.

Os pontos positivos mais citados pelos alunos foram: domínio do conteúdo, relação de amizade com os alunos, preocupação do professor com o bem-estar do aluno, aulas diferenciadas e o empenho de ambas as partes. Descrevemos, aqui, alguns relatos que comprovam a análise realizada. A10 ( $8^{a}$ série): “o empenho de ambos para ter uma boa relação e facilitar, assim, que haja mais conhecimento". A1 (2a série): “vontade de estudar e dedicação”. A14 (8ª série): “as preocupações com o bem-estar dos alunos, a preocupação em preparar coisas diferentes para a sala de aula e, assim, assimilarem melhor o conteúdo". A17 ( $8^{a}$ série): "a boa convivência entre ambos, a amizade fora da escola etc."

Os pontos negativos apontados, de acordo com A17 (8 ${ }^{a}$ série): "o ponto negativo é que se o aluno retruca o professor, vários professores não tentam saber o porquê ele fez isso e já mandam para a diretoria, fa- zendo com que o aluno não goste mais do professor". Como um ciclo vicioso, a falta de respeito perpetua e caso não seja tomada a atitude correta, vai continuar acontecendo. A13 ( $2^{a}$ série) comenta que "nem sempre os professores querem ser amigos da gente, alguns são grosseiros, ignorantes, e, com o tempo, o aluno não tolera mais e essa relação acaba ficando insuportável. Assim, a nota cai junto com a matéria”.

As relações interpessoais entre aluno e professor podem ter como ponto negativo as preferências e regalias quanto ao tratamento, até mesmo com acréscimo de notas, aos alunos que têm uma boa relação com seu professor. Caso o aluno tem algum parentesco, pode ter também benefícios. Contudo, esses apontamentos não levam em consideração o desempenho individual indiferente de quem tem uma boa relação. É claro que, tendo boas notas, mostra os resultados para o professor de seu esforço e se a relação interpessoal é satisfatória, só agrega.

Dados dos alunos da $2^{a}$ série do ensino médio apontam os seguintes resultados em relação às influências das relações interpessoais entre professor e aluno nas notas: 16 alunos responderam que sim, que têm influência nas notas e seis alunos responderam que não têm influência nas notas. Os que responderam "não" alegaram um motivo específico, como mostra o seguinte relato de A16: "não tem por que; independente de boa relação ou não, o aluno recebe a nota que merece devido aos trabalhos e provas".

Doze alunos ( $8^{a}$ série) responderam que têm interferência nas notas, e 15 alunos ( $8^{a}$ série) afirmaram que não têm interferência nas notas. A1: "na minha opinião, não, pois, na sala de aula ou na escola, o professor é um profissional que deve dar a nota que o aluno merece". Um aluno (8a série) respondeu ambas as respostas (às vezes, tem interferência nas notas, e às vezes, não).

Questionados sobre a existência de práticas que incentiva uma boa relação interpessoal entre aluno e professor, tal como dinâmicas, palestras, cursos, entre outros, a turma da $8^{a}$ série apresentou o seguinte resultado: 24 alunos disseram existir práticas de incentivo a uma boa relação. Cinco alunos afirmaram a 
inexistência de práticas de incentivo a uma boa relação e um aluno não respondeu.

A turma da $2^{a}$ série teve como resultado os seguintes dados: 15 alunos responderam que sim, que na escola existem práticas para manter a boa relação entre aluno e professor, e citaram tais práticas como, por exemplo, “gincanas, trilhas ecológicas”. Somente quatro alunos disseram que não, mas não justificaram o porquê.

A partir das respostas obtidas, percebe-se que na escola de Vargeão-SC são realizadas práticas de incentivo às relações interpessoais entre professor aluno, juntamente com a gestão da escola.

Em referência ao professor conseguir lidar bem com os comportamentos dos alunos em sala de aula, a turma da $8^{a}$ série teve como dados: 17 alunos apontaram que sim, cinco alunos que o professor não consegue lidar bem com os alunos desordeiros, outros cinco alunos responderam ambas as respostas (os professores, às vezes, conseguem lidar com a situação dos alunos que não colaboram ou têm bastantes dificuldades, mas, em outras ocasiões, perdem o pulso e acabam tomando medidas mais drásticas para resolver logo a situação) e um aluno não respondeu.

A turma da $2^{a}$ série apresentou como dados: nove alunos comentam que sim, que sabem lidar com o aluno em sala de aula, como afirma o comentário de A10: "sim, sabem lidar da melhor maneira possível, tem controle sobre o aluno". Quatro alunos responderam às vezes, pois nem sempre conseguem manter 0 controle e seis alunos responderam que o professor não consegue agir corretamente com os mais variados tipos de comportamento dos alunos. Eles relatam a falta de atitude dos professores. Vejamos o depoimento de A1: "falta paciência e experiência para com o aluno problemático". E A5: “dizem que, muitas vezes, o professor tem 'compaixão' pelo aluno, por ele ter feito algo errado, e se ferram".

$\mathrm{Na}$ turma da $8^{\mathrm{a}}$ série, nas matérias em que os alunos têm maior dificuldade de aprendizado, eles consideram que a relação com o professor tem influência direta no seu aprendizado; é consideravelmente menor em relação aos alunos que consideram ter influência direta: oito alunos responderam que tem influência direta no seu aprendizado, 18 alunos responderam que não tem influência direta no seu aprendizado, um aluno colocou as duas proposições (afirmou que ocorre às vezes, tendo influência, e às vezes não tendo influência nos conhecimentos que aprende em sala de aula) e um aluno não respondeu.

Em relação ao interesse apresentado nos estudos da disciplina que o professor que leciona não tem um bom relacionamento aluno e professor, a turma da $8^{a}$ série apontou que 20 alunos apresentaram interesse em estudar a matéria, que não têm um bom relacionamento com seu professor, porque consideram de suma importância passar de ano e sua dedicação é que vai proporcionar o seu bom desempenho, não necessariamente a sua relação com o professor. Sete alunos mostraram que não têm interesse nenhum em estudar a matéria e, que o interesse que detinham é consideravelmente diminuído - esse dado leva, muitas vezes, à reprovação, pois é necessário passar em todas as matérias para seguir na turma posterior. $E$ um aluno não respondeu.

Na turma da $2^{a}$ série do ensino médio matutino, apresentaram-se os seguintes dados: 17 alunos comentam que o relacionamento com os professores influencia no interesse por estudar determinada matéria. Vale ressaltar que, influenciando, eles comentam que, assim, se faz necessário estudar para ter um futuro melhor.

Vejamos alguns comentários que comprovam tal afirmação. A21: “independente da relação com o professor, a gente tem que estudar se quiser ser alguém na vida”. A10: “independente se a relação é boa ou ruim, isso não deve atrapalhar na aprendizagem da matéria". Sete alunos descrevem que não têm interesse em estudar a matéria em que não se tem um bom relacionamento com o professor - relatam que estudam apenas para obter boas notas e passar de ano. Vejamos o relato de A22: "é muito ruim, pois a gente não se sente bem diante de alguém de mau caráter”.

Nas maiores causas de conflitos entre os professores e alunos, obtiveram-se respostas muito similares entre as turmas da $8^{a}$ série e da $2^{a}$ série. A indisciplina 
é um fator que prejudica bastante; deixa os colegas que querem prestar atenção impacientes e desconcentrados; faz a professora ficar nervosa, perdendo o rumo do assunto. Nessa tomada de providências quanto aos alunos indisciplinados, perde-se tempo e se ganha mais estresse.

A pedagogia tradicional enfatizava bastante a disciplina, memória e autoridade, isso passou a ser visto como cerceador da liberdade dos alunos, preconizando-se que a disciplina externa deveria ser abolida em favor do desenvolvimento da disciplina interna. (SAVIANI, 2010, p. 180).

Muitas mudanças ocorreram na educação, o que forneceu maior liberdade para os alunos e a indisciplina teve elevados índices. 0 espírito crítico do aluno não pode ser perdido, mas sua postura está deixando a desejar: a sala de aula é um espaço para se estudar, não um cômodo da casa do aluno, no qual ele faz o que quer, na hora que deseja. Os alunos devem mudar essa postura, pois a sociedade não vive sem regras. Com isso, é preciso bastante investimento na educação: o ensino ainda tem muito de ser reformado, com investimento em pessoal e materiais apropriados para o ensino-aprendizagem.

Tais informações são apontadas pelos alunos, tal como A6: "conversas paralelas e a bagunça em sala de aula, além de pouca dedicação entre professores e alunos, e falta de compreensão/diálogo". E A22 ( $2^{a}$ série) ressalta que ocorrem desentendimentos devido às opiniões contrárias.

As projeções quanto ao ideal da relação aluno e professores na escola pesquisada, das turmas da $8^{a}$ série do ensino fundamental e $2^{a}$ série do ensino médio, revelam que os alunos gostariam que a relação aluno e professor contivesse mais respeito mútuo. Vejamos alguns relatos dos alunos da segunda série do ensino médio. A2: "gostaria que os professores fossem mais amigáveis, que eles não se sentissem tão superiores e tentassem ser mais companheiros dos alunos". A5: "que o lado pessoal dos professores não se misture com o lado profissional”. A16: “assim como nós (alunos), que eles (professores) engolissem alguns xingamentos, sem descontar nos alunos".

No quesito dedicação de professores e alunos para uma melhor relação, A21 aponta que "os professores fossem mais legais, e que os alunos não incomodassem tanto". A ética e deveres para alunos e professores são citados por Santos (2015, p. 540-541):

\begin{abstract}
0 professor deve motivar o aluno, estar atento às necessidades do aluno, em cada encontro procurar transmitir um conhecimento novo, ser justo nas avaliações, respeitar o aluno, acreditar na capacidade do aluno, procurar ser amigo do aluno. 0 aluno não deve julgar o professor, não deve competir com o professor, o ideal é que os alunos tentem estabelecer uma relação de plena igualdade, esquecendo-se que o professor necessariamente deve exercer autoridade e disciplina na turma, prestando atenção na aula, estudando para trabalhos e provas, ademais a colaboração de ambas as partes professor e aluno.
\end{abstract}

A relação estabelecida entre os próprios alunos é um fator que interfere nas relações entre professor e aluno. Existe uma discriminação quanto ao negro/ portador de necessidade especial ou que sabe um pouco menos/fraco e também a inveja ou idolatria quanto aos nerds/fortes/ricos. Assim, a turma deve evitar tais comportamentos e fazer essas distinções pessoais se tornarem favoráveis. Existem tantas diferenças físicas, comportamentais, étnicas e intelectuais que é banal inferiorizar ou se enaltecer mediante tais comparações. Por isso, deve existir maior entendimento e auxílio entre os colegas, porque, em grande parte, depende do aluno passar de ano e, para que se concretize isso, é necessário que tenha em mente o ensino-aprendizagem que deve conhecer e aprender; isso só é proporcionado com a ajuda do professor e, se preciso, dos colegas e pais.

A partir desta pesquisa, considerando todos os dados levantados podemos comprovar a relevância das relações interpessoais entre professores e alunos, principalmente quando se trata do aprendizado do aluno e da satisfação pessoal e profissional do professor. As informações extraídas ainda contêm vácuos. Para um resultado mais concreto, seria pertinente laços contínuos, num emaranhado de estudos. 


\section{CONSIDERAÇÕES FINAIS}

0 estudo buscou conhecer quais são os fatores que permeiam as relações interpessoais entre professores e alunos de uma escola de educação básica de Vargeão-SC. Os resultados apontaram que, mediante acontecimentos negativos nas relações interpessoais em sala de aula, as professoras questionadas buscam jeitos de contornar a situação, porque veem a necessidade das boas relações para o ensino-aprendizagem. Em contrapartida, quanto ao posicionamento de buscar melhorias nessas relações, é passado para os alunos parte da responsabilidade. Mediante essa situação, desvirtua-se do foco: a maioria dos alunos está insatisfeita, e, diante da insatisfação, poucos procuram mudar tal situação.

Diante da busca dos fatores que condicionam uma boa relação interpessoal ou mesmo que levem a ocorrer relações interpessoais desgastantes, ressaltam-se pontos determinantes que poderiam estabelecer melhores relações e outros pontos que, retirados, somente agregariam valores e posicionamentos favoráveis. Os alunos revelaram que o domínio do conteúdo, a didática atrativa, juntamente com a preocupação dos professores com o bem-estar dos alunos, são fatores muito positivos.

Em referência ao que está prejudicando as relações, os professores apontam que existe falta de compreensão quanto ao que acontece em sala de aula, comprovado pelo pouco respeito e falta de interesse dos alunos. Quanto aos professores, existe a preferência de agrado para com os alunos de bom desempenho ou vínculo externo da instituição, o que provoca inveja e é visto como prejudicial, porque alunos que vão mal consideram tal relacionamento corrupto quanto às notas.

Ainda, é importante destacar que muitos alunos afirmam que os professores têm atitudes autoritárias e são vistos como pessoas que se consideram num patamar de superioridade. Os alunos esperam que os professores baixem a guarda e sejam mais afetuosos, pois eles vão se sentir mais motivados e pensam que poderão melhorar o processo de aprendizagem.

Os alunos, considerando que o importante das relações interpessoais no ambiente escolar é melhorar o pro- cesso de ensino-aprendizagem, destacam que, mesmo tendo falta de uma boa relação, buscam cumprir os seus compromissos, pois buscam a aprovação no ano letivo.

Mostrou-se necessário que os professores devem ter domínio do conteúdo, mas, acima de tudo, saber contornar as diversas situações que permeiam o espaço da sala de aula. Afinal, o que o professor faz e o modo como age no ambiente escolar, seja lecionando ou nas situações adversas, produzem reflexos nos seus alunos, e nessa consciência do bom ensinar do professor e da aceitação dos alunos, os frutos produzidos serão colhidos em algum momento, considerando que o bem-estar propiciado é incalculável tanto para o professor quanto para o aluno. Por isso de valorar as boas relações interpessoais no contexto escolar.

Ressalta-se que as acadêmicas pesquisadoras farão o compartilhamento das informações obtidas, uma vez que todos os questionados se prontificaram a preencher os dados em auxílio ao projeto. Tal proposta é para os alunos e os professores tomarem conhecimento do que acontece e refletir sobre os dados. Espera-se que por decisão pessoal, tanto dos alunos como dos professores, todos procurem melhorar as relações interpessoais, o que só vai beneficiá-los e qualificar o processo de ensino-aprendizagem.

\section{REFERÊNCIAS}

MARCHESI, Álvaro. $\mathbf{0}$ bem-estar dos professores: competências, emoções e valores. Porto Alegre: Artmed, 2008.

SANTOS, William Douglas Resi. Como passar em provas e concursos: tudo o que você precisa saber e nunca teve a quem perguntar. 28.ed., rev. e atual. Rio de Janeiro: Impetus, 2015.

SAVIANI, Dermeval. Interlocuções pedagógicas conversa com Paulo Freire e Adriano Nogueira e 30 entrevistas sobre educação. Campinas-SP: Autores Associados, 2010. 
Recebido em: 19 de dezembro de 2015 Avaliado em: 18 de março de 2016 Aceito em: 21 de maio de 2017
1 Acadêmica do curso de Ciências Biológicas, da Universidade do Oeste de Santa Catarina - UNOESC Xanxerê. E-mail: daialandoperuzo@gmail.com. 2 Acadêmica do curso de Ciências Biológicas, da Universidade do Oeste de Santa Catarina - UNOESC Xanxerê. E-mail: angelica_sikeiraa@live.com.

3 Professora dos cursos de Licenciatura, da Universidade do Oeste de Santa Catarina - UNOESC Xanxerê. E-mail:sonia.alberici@unoesc.edu.br 